\title{
Pharmacognostic and Phytochemical Standardization of White Tea Leaf (Camellia sinensis L. Kuntze) Ethanolic Extracts
}

\author{
Meiliza Ekayanti, Lia Ardiana, Sarah Zielda Najib, Rani Sauriasari, Berna Elya*
}

\begin{abstract}
Background: Tea or also known as Camellia sinensis (Theaceae family) is the most popular plant and beverage in the world because of the sensory properties, prices are relatively cheap, stimulant effects, and their potential health benefits but white tea is not widely known. White tea is made from unfermented tea leaves young shoots protected from sunlight to avoid polyphenols degradation which inhibits of the chlorophyll formation and causing the white color on the leaf buds. Objective: The objective of research and development of herbal medicine is to improve the quality and safety of natural products. Materials and Methods: Macroscopical and microscopical features of the leaf have been analysis using an optical microscope and fragment analysis under scanning electron microscopy (SEM). Phytochemical and physico-chemical analysis were evaluated. The observation of the FTIR spectrum profiles is done by interpreting the typical peak that appears. Results: The leaf has actinocytic stomata, unicellular trichomes, heterogenous mesophyll which is characterized by the presence of calcium oxalate crystals and sclereid cells. Phytochemical analysis indicated resources the presence of tannins, flavonoids, glycosides and saponins. The content of polyphenol from white tea leaves ethanolic extract is $35.73 \%$ with the largest concentration of catechins is $18.84 \%$ and $17.43 \%$ tannins. The derivative content of catechins is EGCG with $7.37 \%$. FTIR analysis showed functional groups of $\mathrm{O}-\mathrm{H}, \mathrm{C}-\mathrm{H}, \mathrm{N}-\mathrm{H}, \mathrm{C}=\mathrm{O}, \mathrm{C}=\mathrm{C}$, and $\mathrm{C}-\mathrm{O}$. Conclusion: Pharmacognostic and phytochemicals features established in this study may be used as part of the pharmacopoeial standard which can play an important role in its standardization.
\end{abstract}

Key words: Characteristic, Macroscopic, Microscopic, Physico-chemicals, Phytochemicals, Theaceae.

\section{Meiliza Ekayanti, Lia Ardiana, Sarah Zielda Najib, Rani Sau- riasari, Berna Elya* \\ Faculty of Pharmacy, Universitas Indo- nesia, 16424, Depok, INDONESIA. \\ Correspondence \\ Berna Elya \\ Faculty of Pharmacy, Universitas Indone- sia, 16424, Depok, INDONESIA. \\ Phone: +62 21-727-0031/ \\ +62 813-1416-1497 \\ E-mail: berna.elya@gmail.com}

\section{History}

- Submission Date: 21-12-2016;

- Review completed: 05-01-2017;

- Accepted Date: 11-11-2017.

DOI : 10.5530/pj.2017.2.37

Article Available online http://www.phcogj.com/v9/i2

\section{Copyright}

(C) 2017 Phcog.Net. This is an openaccess article distributed under the terms of the Creative Commons Attribution 4.0 International license.

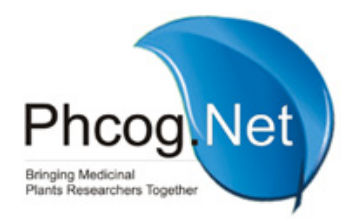

\section{INTRODUCTION}

The development of herbal medicines for health purposes in Indonesia at this time is likely to increase rapidly. The use of herbal medicine is intended to improve health (promotion), restoring health (rehabilitative), disease prevention (preventive) and healing (curative) and is expected to support the development of public health. This condition supported by the potential of Indonesia's natural resources which is consisting of 30,000 species of medicinal plants. More than 6000 species of medicinal plants have been used a source of natural medicine that empirically has been used as traditional medicine. ${ }^{1}$

Tea is the most popular plant and beverage in the world because of the sensory properties, prices are relatively cheap, the stimulant effects and their potential health benefits. ${ }^{2}$ Tea or also known as Camellia sinensis (Theaceae family) are widely cultivated commercially but white tea is not widely known. Based on their processing, tea can be divided into unfermented tea (white tea and green tea), semi-fermented tea (oolong tea), and fermentation (black tea). ${ }^{3}$ White tea has a simplest process by withering and drying. White tea leaf is taken from the shoots or very young tea leaves or buds and covered with silvery hair. The young shoots are protected from the sunlight which inhibiting of the chlorophyll formation and causing the white color on the leaf buds.

White tea is reported to have a high polyphenol content and showed antiseptic and antioxidant proper- ties. ${ }^{4}$ In addition, various types of bioactive found in white tea leaves such as polyphenols, caffeine, theogallin, gallic acid, theaflavins, flavonols glycoside, and catechins especially epigallocatechin (EGC), epigallocatechin gallate (EGCG), epicatechin gallate (ECG), and gallate epicatechin (GEC). ${ }^{4-6}$ The antioxidant properties of white tea can prevent free radicals and inhibit oxidative stress and inflammation. ${ }^{7} \mathrm{Oxi}^{-}$ dative stress and inflammation associated with various diseases including obesity disease, dyslipidemia, diabetes, cardiovascular, neurodegenerative and cancer. ${ }^{2,4}$ The previous studies reported that ethanolic extract of white tea has antidiabetic in vitro activity by inhibition of alpha-amylase enzyme activity (\% inhibition of 99.11 \pm 0:01), alpha-glucosidase (IC50 10.54 $\mathrm{mg} / \mathrm{mL}$ ) and dipeptidyl peptidase IV (\% inhibition $30.57 \pm 0.08){ }^{8}$ It is necessary to develop and further studies of white tea leaves.

The objective of research and development of herbal medicine is to improve the quality and safety of natural products. Therefore, it is necessary to standardize raw materials and extracts to maintain the uniformity of quality, safety and efficacy. Raw material quality parameters include moisture content, ash content, acid insoluble ash, water soluble extract content, content of ethanol soluble extract and concentration of substances identity. It also conducted organoleptic, microscopic, macroscopic, chemical content identification, fingerprint profiles, and contamination analysis. ${ }^{9}$ Standardization of white tea leaf extract is 
necessary to provide information on quality standards of herbal medicine development.

\section{Experimental}

\section{Preparation of Material}

White tea leaves (Camellia sinensis L. Kuntze) obtained from the Tea Plantation and Quinine Research Center in Gamboeng, West Java, Indonesia. White tea leaves were sorted, collected, and then dried under sunlight. Furthermore, the tea leaves are withered with a dryer. The white tea leaves powder are made by grinding dried white tea leaves by using a grinder.

\section{Preparation of White Tea Extract}

White tea leaves extract prepared by reflux method using ethanol $70 \%$ as a solvent over 3 hours in $60^{\circ} \mathrm{C}$. After 3 hours the extract was filtered and the supernatant was removed and transferred to a volumetric flask then be repeated reflux for 2 (two) times. The ethanol extract then evaporated using a vacuum rotatory evaporator.

\section{Identification of Raw Materials}

Identification of raw materials conducted by observation of organoleptic, macroscopic and microscopic identification. Macroscopic identification of white tea leaves was observed based on the length and width of leaves, plant height, color and description of the leaves and stems. Leaf color is identified before and after the drying process by using a Microscope IX70. Microscopic identification is done by using cut crosswise and lengthwise of leaf and dried powder white tea leaves. Identification of raw materials powder is also done using field emission scanning electron microscopy (FE-SEM). Previously, powder coating with gold for 1 minute then identified with the FE-SEM.

\section{Extract Characterization}

Characterization of the extract was conducted on the determination of moisture content, ash content, acid insoluble ash content, water-soluble extract content, and ethanol-soluble extract content. The extract characterization method conducted to the WHO guidelines. ${ }^{9}$

\section{Phytochemical Analysis}

Phytochemical analysis conducted by screening chemical substances and determination of major compounds. Identification of the presence of alkaloids, flavonoids, tannins, saponins, glycosides, terpenoids and anthraquinone was carried out according to the procedures in $\mathrm{WHO}$ guidelines and Harborne. ${ }^{9,10}$

Determination of polyphenol content was measured by spectrophotometry method using gallic acid as a standard, and the results expressed as a percent of gallic acid equivalents. The amount of $10 \mathrm{~g}$ sample is weighed into a $100 \mathrm{ml}$ flask, dissolved in $50 \mathrm{ml}$ of distilled water and sonication for 10 minutes, then add with distilled water until $100 \mathrm{ml}$. one milliliter aliquot transfers to a flask. Added $5 \mathrm{ml}$ of a reagent of Folin Ciocalteau $10 \%$ and let stand for 3-8 minutes, then added $4 \mathrm{~mL}$ of $7.5 \%$ sodium carbonate and homogenized. The mixture incubated for 2 hours protected from light. Furthermore, the absorbance of the solution is measured by spectrophotometer at $750 \mathrm{~nm}$.

Determination of total tannin content was measured by spectrophotometry method. The amount of $1 \mathrm{~g}$ sample is weighed and put into a flask of $100 \mathrm{ml}$ and diluted with distilled water. One milliliter aliquot put into a flask, then diluted with $75 \mathrm{ml}$ of distilled water. Added $5 \mathrm{ml}$ of reagent Folin-denis, $10 \mathrm{ml}$ of saturated sodium carbonate solution, and distilled water till $100 \mathrm{ml}$ and then homogenized. This mixture incubated for 30 minutes and absorbance was measured at $760 \mathrm{~nm}$.

\section{Determination of Catechin and EGCG}

Determination of total catechin was measured by using spectrophotometry at $210 \mathrm{~nm}$. Catechin as a standard, the results expressed as a percent of catechins equivalents. While EGCG assay was conducted using reverse phase HPLC using the mobile phase isocratic elution system that is a mixture of orthophosphate $0.1 \%$, water, acetonitrile, methanol (14:7:3:1 $\mathrm{v} / \mathrm{v})$ at $\mathrm{pH}=4.00$ with a flow rate of $1.2 \mathrm{~mL} / \mathrm{min}$ and detected at $280 \mathrm{~nm}$.

\section{Chromatography Analysis}

Chromatography analysis was done using a Thin Layer Chromatography (TLC) system. Ten microliters of white tea ethanolic extract and five microliters catechins standard were applied on chromatographic precoated silica gel plates (Merck, TLC grade) as the stationary phase. The chromatograms were developed in twin trough glass chamber containing toluene, acetone, and formic acid (5:4:1 v/v) as the mobile phase. The plates were removed after the solvent front has moved from the original position to the finish line and subsequently allowed to dry. After drying, the plate was sprayed with iron (III) chloride $\left(\mathrm{FeCl}_{3}\right) 1 \%$. The plate then visualized under visible light (white) and short UV (254 nm) light. The amount that each component of a mixture travels can be quantified using retention factors (Rf). Values were calculated for each spot using the formula:

\section{$\mathrm{Rf}=$ Distance from the starting point to the center of the spot}

\section{Distance from the starting point to the solvent front} Contamination Analysis

Contaminant analysis was determined by measuring heavy metal content using AAS method, and pathogenic microbial contamination such asE. coli, Salmonella sp., and Pseudomonas aeruginosa.

\section{Examination of Fourier Transform Infrared Spectroscopy (FTIR)}

FTIR spectrum components conducted by squirting liquid extract on the surface of a very thin salt plate, for example, potassium bromide, then a second plate is placed on the first plate to spread a thin layer of liquid between the plate. Furthermore, the spectra obtained with the aid of spectrophotometer and software that is attached to the tool.

\section{RESULTS}

The characterization of organoleptic observation including shape, smell, color and taste of Camellia sinensis L. Kuntze leaves. White tea has a distinctive aroma and astringent taste as same as the other tea. The macroscopic examination of the leaf consists of botanicals characteristic observation. However, the microscopic examination was carried out with cross-section observation of leaf or specific part fragment of leaf powder. The purpose of this observation is to examine specific parts contained in the organs of plants used. ${ }^{11,12}$

Macroscopic characteristic of Camellia sinensis (L.) Kuntze showed that the leaves are glossy dark green, alternate, short-petiole, coriaceous, lanceolate or elongated-ovate, and roughly serrate. The leaf blade is 6-18 $\mathrm{cm}$ long, 2-6 cm wide, short-stemmed, alternate layout, stiff leaves, elongated ellipse-shaped with finely toothed edges, and pinnately netted venation. ${ }^{11}$ Mature leaves are bright green colored, smooth, and leathery (Figure 1B). While young leaves appear silver because of the covering of short downy hair on the underside (Figure 1C).White tea leaves are as same as the Camellia sinensis (L.) Kuntze leaves but still rolled up, oval, like a needle with a length of $1.5-3 \mathrm{~cm}$, diameter $1-2 \mathrm{~mm}$, and the surface is covered with hairs which are very delicate (Figure 2A). Dried white tea leaves color are silvery-white (Figure 2B).

The observation of cross sections of Camellia sinensis (L.) Kuntze leaves under a microscope, found the cuticle, epidermis, mesophyll, crystals of Calcium oxalate, sclereid cell, and trichomes (Figure 3). Upper epider- 
mal cells are large, distinctly visible with undulating walls, and simple hairs (unicellular trichomes non-glandular) pointed, undivided, and also very long but not found stomata. The lower epidermis larger than those of the upper surface. The mesophyll is heterogeneous and asymmetrical, it is characterized by the presence of sclereid cells and crystals of Calcium oxalate (Figure 3E and Figure 3F). The type of sclereid cell is Astro sclereid with branched, pointed, irregular (often star-shaped). Parenchymal cells similar to those of most other leaves, and not very distinctive (Figure 3D).

While in the observation of a longitudinal cross section of the tea leaves showing trichomes (hairs on the lower epidermis cells), stomata, and sclereid cell (Figure 4). The type of stomata is actinocytic, the variant type of diacytyic stoma with two reniform cells (guard cells), oval or nearly round, regularly surrounded by 4 or more tangential elongated cells (Figure 4B). Microscopic observation of the powder found any fragments of leaves and a layer quiet lot of fine hairs, (Figure $5 \mathrm{~A}$ ) and it is showed under field emission scanning microscopy (FE-SEM) analysis (Figure 5B). Young buds leaves are cover with a lot of hairs and it giving the distinctive of tea aroma.

Extracts of white tea leaves were obtained using ethanol $70 \%$ with reflux extraction method at $60^{\circ} \mathrm{C}$. The yield of the extract is $57.08 \%$. The crude extract obtained was red-brownish with a distinctive aroma of tea. The extract examination was conducted by physicochemical and phytochemical examination. TLC profile is one of the examination methods to analyze the presence of marker compound from the extract. The TLC profiles of white tea extract and catechin standard were obtained under UV 254 light after post-derivatization with $\mathrm{FeCl}_{3} 1 \%$. Figure 6 showed the catechin spot in the white tea extract specifically. Distinct TLC spot on the silica gel plate representing isolated compound with specific $\mathrm{Rf}$ values $(\mathrm{Rf}=0.56)$.

Physicochemical examination of the extract included the content of moisture, ash, acid insoluble ash, water-soluble extract, ethanol-soluble extract (Table 1). Phytochemical analysis of the extract showed the presence of alkaloids, flavonoids, tannins, glycosides, saponins. The result for terpene/steroid and anthraquinone was negative. ${ }^{10}$ The content of polyphenol from white tea leaves ethanolic extract is $35.73 \%$ with the largest concentration of catechins is $18.84 \%$ and $17.43 \%$ tannins. The derivative content of catechins is EGCG with 7.37\% (Table 2).

Description: + = detected; - = undetected

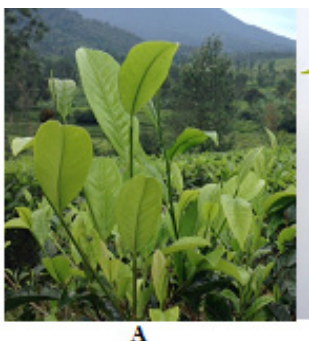

A

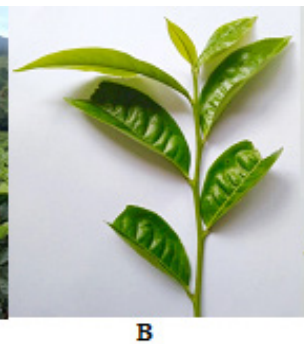

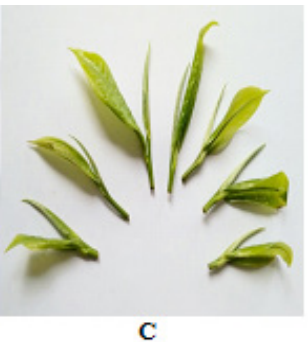

C
Figure 1: A. Field view of Camellia sinensis (L.) Kuntze, plant; B. fresh tea leaves; and C. shoots.
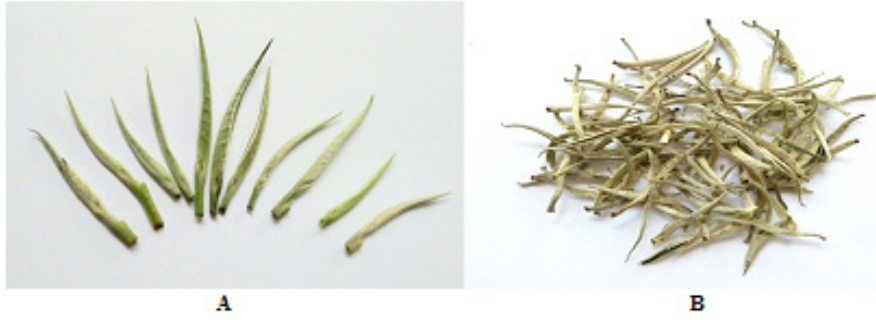

Figure 2: A.Fresh white tea leaves; and B.Dried white tea leaves.

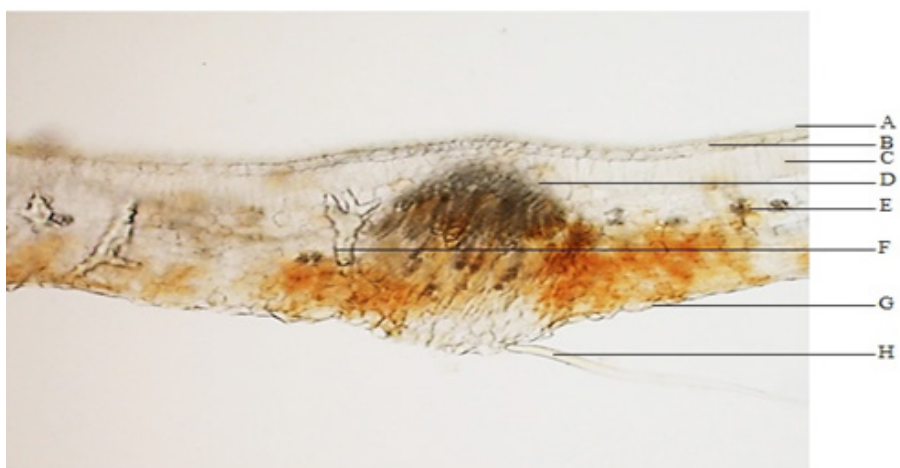

Figure 3: The Observation of leaves Camellia sinensis (L.) Kuntze using IX70 Microscope Leaf: Cross section: A.cuticle, B.upper epidermis, C.mesophyll, D.parenchyma, E.crystal of Calcium oxalate, F.sclereid cell, G.lower epidermis cell, H.trichome.

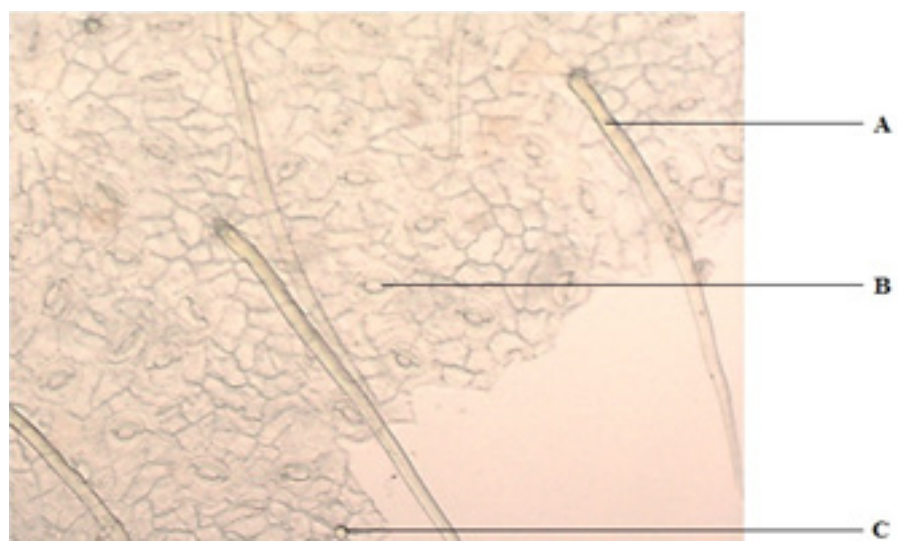

Figure 4: The observation of longitudinal cross section leaves using Microscope IX70 Leaf: Longitudinal cross section: A. trichome, B. stomata, C. sclereid cell.

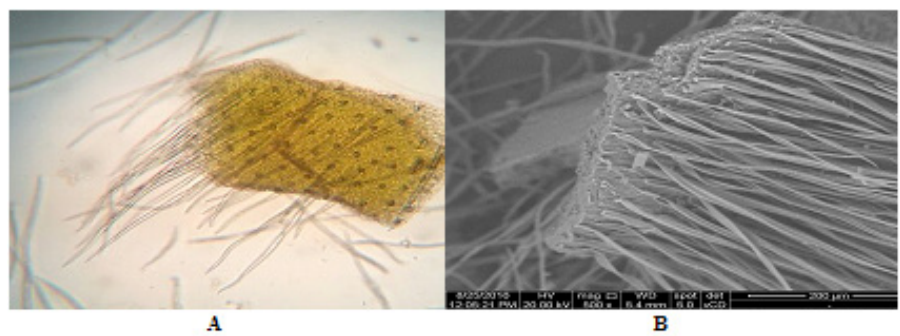

Figure 5: Microscopic observation of the white tea leaves powder White tea leaf: Powder: A. Hairs fragment observation of white tea leaves powder using microscope IX70 and B. Hairs fragment observation under FE-SEM.

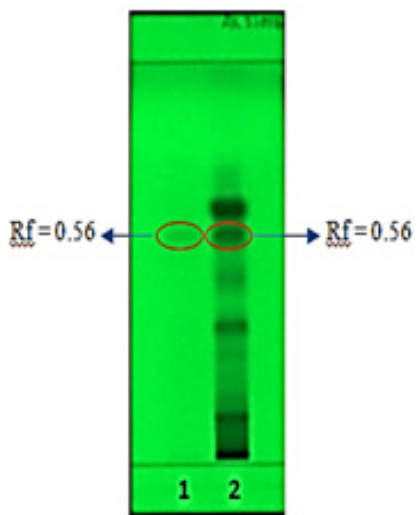

Figure 6: Figure 6: TLC chromatogram of white tea ethanolic extracts Extract: Spot: 1. Catechins standard, 2. white tea ethanolic extract 
Table 1: Characterization of ethanolic extract of white tea leaves ( $\mathrm{Ca}$ mellia sinensis (L.) Kuntze)

\begin{tabular}{ccc}
\hline No. & Physico-chemical Parameter & Result (\%) \\
\hline 1. & Moisture content & 16.03 \\
2. & Ash content & 6.04 \\
3. & Acid insoluble ash content & 0.12 \\
4. & Water-soluble extract content & 17.18 \\
5. & Alcohol soluble extract content & 33.31 \\
\hline
\end{tabular}

Table 3: Contaminant Result of White Tea Ethanolic Extract

\begin{tabular}{cccc}
\hline No. & Parameter Test & Result & Unit \\
\hline 1. & $\mathrm{~Pb}$ & $\mathrm{ND}^{*}$ & $\mathrm{ppm}$ \\
2. & $\mathrm{As}$ & $\mathrm{ND}^{*}$ & $\mathrm{ppm}$ \\
3. & $\mathrm{Cd}$ & $0.042^{* *}$ & $\mathrm{ppm}$ \\
4. & Negative & Colonies/unit \\
5. & E. coli & Negative & Colonies/unit \\
6. & Pseudomonas aeruginosa & Negative & Colonies/unit \\
\hline
\end{tabular}

Description: ${ }^{\star} \mathrm{ND}=$ not detected; ${ }^{*}$ Requirements level of Cd $£ 0.3 \mathrm{ppm}$
Table 2: Phytochemical Analysis of White Tea Leaves Ethanolic Extract

\begin{tabular}{ccc}
\hline No. & Phytochemical Parameter & Result \\
\hline 1. & Alkaloids & + \\
2. & Flavonoids & + \\
3. & Tannins & + \\
4. & Glycosides & + \\
5. & Saponin & + \\
6. & Terpene/ steroid & - \\
7. & Anthraquinone & - \\
8. & Total polyphenol & $35.73 \%$ \\
9. & Total tannin & $17.43 \%$ \\
10. & Total Catechin & $18.94 \%$ \\
11. & EGCG content & $7.37 \%$ \\
\hline
\end{tabular}

Description: + = detected; - = undetected

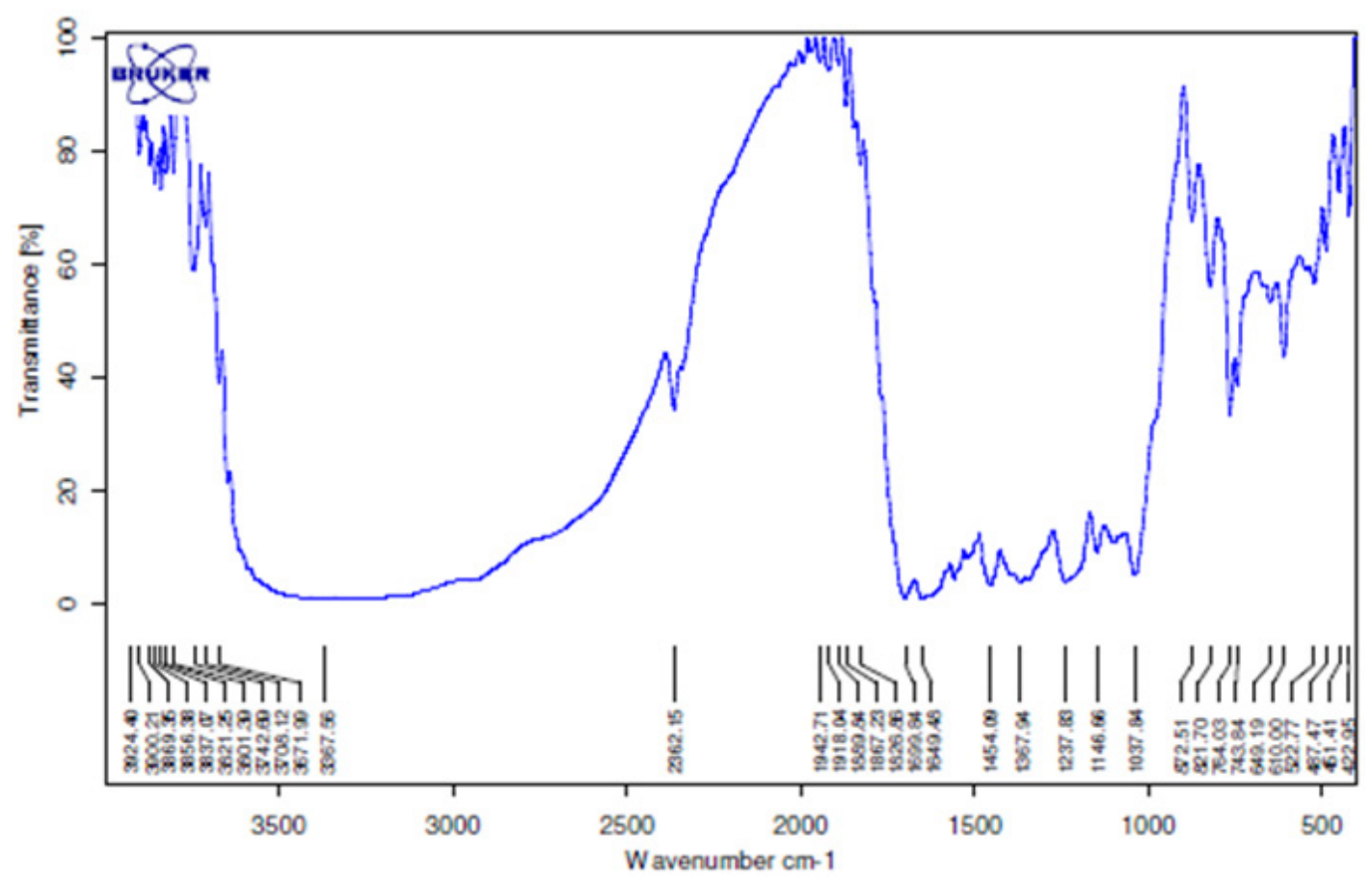

Figure 7: FTIR Spectra of White Tea Ethanolic Extract

Table 4: FTIR Region Spectra of White Tea Ethanolic Extract

\begin{tabular}{cccc} 
Bond & Compound & $\begin{array}{c}\text { Frequency Area } \\
\left(\mathbf{c m}^{-1}\right)\end{array}$ & Intensity \\
\hline O-H & Phenol, Alcohol & $3500-3650$ & Medium, broad \\
C-H & Aromatic & $690-900$ & Strong \\
N-H & Amine, Amide & $3300-3500$ & Medium \\
C=O & Carbonyl & $1820-1660$ & Strong \\
C=C & Alkene & 1650 & Weak \\
C-O & Ester & $1300-1000$ & Strong \\
\hline
\end{tabular}

The contaminant analysis was observed by analyzing the heavy metals and pathogenic bacterial content. Parameters on heavy metal analyzing includingPlumbum (Pb), Arsenic (As), and Cadmium (Cd) (Table 3). Based on the literature, results obtained that heavy metal contamination has been qualified ${ }^{9}$ Furthermore, neither pathogenic bacteria such as Escherichia coli, Salmonella sp., nor Pseudomonas aeruginosa detected. The FTIR spectra of white tea ethanolic extract were obtained with the infrared radiation region is $4000-400 \mathrm{~cm}^{-1}$ (Figure 7).

Observation of the FTIR spectrum profiles is done by interpreting the typical peak that appears. The interpretation of FTIR spectra profile showed that the white tea ethanolic extract composed organic com- 
pounds which mostly containing functional groups $\mathrm{O}-\mathrm{H}$ from phenolic or alcohol with medium and broad spectrum, $\mathrm{C}-\mathrm{H}$ aromatic, $\mathrm{N}-\mathrm{H}$ amine or amide, $\mathrm{C}=\mathrm{O}$ carbonyl, $\mathrm{C}=\mathrm{C}$ alkene, and $\mathrm{C}-\mathrm{O}$ ester (Table 4).

\section{DISCUSSION}

Macroscopic and microscopic characters are one of the important criteria for identification. The analysis of the chemical and physical standards are the confirmatory tests for identification. The leaves size is the main criterion for the classification of tea plants, which is the type of the tea leaves are characterized by intermediate size. The different leaf ages produce different tea qualities since their chemical compositions are different. The results of the stomata distribution showed that between stomata and distribution in the leaves are hypostomatic. Stomata associated to photosynthesis to produce food for plants. Stomata is the entrance of $\mathrm{CO}_{2}$ which is one of the raw materials in the process of photosynthesis. Photosynthesis also altering the synthesis of secondary metabolites in tea plant including catechin, and also polyphenol was correlated to the weather. ${ }^{13}$ It causes the relation between the photosynthesis and secondary metabolites content such as catechins.

The presence of a lot of unicellular trichomes on both sides of the white tea leaf creates a microenvironment of water vapor around the leaf. Calcium oxalate crystals are one of the characteristic of the tea leaves and the presence of the crystalline associated with the photosynthesis rate. The white color of the white tea leaf because the chlorophyll has not been formed. White hair that covers the surface coloring white to the leaves when it has been dried.The result of macroscopic and microscopic characterization of the leaves can determine the anatomical structures of plant metabolite storage. ${ }^{13}$

The quality of herbal medicines relies on their bioactive constituents. Therefore, TLC fingerprinting serves as an important and powerful tool for standardization and determination bioactive compounds. White tea leaves extract represented the distinctive TLC spots that similar to the $R f$ values of the catechin. The composition of polyphenol as catechin reported was higher (major compound), it is indicated that astringency was mainly determined by the content of catechins and the other phenolic compounds. ${ }^{13}$ White tea leaves have a simple processing without any fermentation process and higher content of polyphenols especially catechins derivatives. It has been confirmed by the determination of the polyphenol, catechins, and EGCG content.

According to the results of the phytochemical analysis in white tea leaves extract, there is the presence of alkaloid, flavonoid, tannin, and saponin. Various types of bioactive found in white tea same as those found in green tea (polyphenols, caffeine, theogallin, gallic acid, theaflavins, glycoside flavonols, and catechins). Main catechins found in white tea are EGC, EGCG, ECG and EGC which are higher than green tea. ${ }^{3,5}$ White tea leaves extract contains the high concentration of catechins and low concentration of theaflavin and thearubigin (an oxidation product of polyphenol oxidase) and it is related to the color of tea. ${ }^{14}$ However, each type of tea has a number of different content depending on tea processing, geographic location, and growth condition of the tea plant. ${ }^{2}$

Polyphenols compound in tea is a powerful antioxidant agent and positive effect on health. Several studies have been conducted that white tea as an inhibitor of pancreatic lipase activity more effective that green tea. ${ }^{15}$ White tea leaves extract was reported to inhibit adipogenesis and stimulate lipolytic activity. ${ }^{16}$ Another study also reported that white tea leaves ethanolic extract has an antidiabetic activity as inhibitor a-glucosidase, $\alpha$-amylase, and dipeptidyl peptidase IV. ${ }^{8}$

\section{CONCLUSION}

The current study revealed that the result of macroscopic and microscopic characterization of the leaves can determine the anatomical structures of plant metabolite storage. The present work can be used to provide data about the pharmacognostic characteristics of the white tea leaves of $\mathrm{Ca}$ mellia sinensis L. Kuntze that proves the importance of these results. This study will be helpful in the pharmacognostic and phytochemical identification of white tea leaves extract, also the result of identification will be fingerprinted for the proper identification of crude drugs from white tea leaves and provide pharmacological preparation in the future.

\section{ACKNOWLEDGEMENTS}

The authors thank Hibah Pitta Grant, Universitas Indonesia for research funding. Acknowledgment is also due to all their colleagues for their high prestigious encouragement in accomplishing this task.

\section{CONFLICT OF INTEREST}

The authors have no conflict of interest to declare.

\section{REFERENCES}

1. Elfahmi, Woerdenbag HJ, Kayse O. Jamu: Indonesian Traditional Herbal Medicine Towards Rational Phytopharmacological Use: Review, Journal of Herbal Medicine. 2014:4:51-73. https://doi.org/10.1016/j.hermed.2014.01.002.

2. Dias TR, Thomas G, Teixeira NF, Alves MG, Oliveira PF, Silva BM. White Tea (Camellia sinensis (L.)): antioxidant properties and beneficial health effects. International Journal of Food Science, Nutrition, and Dietetics. 2013:2(2):19-26.

3. Rohdiana D. Tea: Processes, characteristics, and functional components. Food review Indonesia, August 2015:8.

4. Alcazar. Differentiation of green, white, black, Oolong, and Pu-erh teas according to their free amino acids content. Journal of Agricultural and Food Chemistry. 2007:55(15):5960-65. https://doi.org/10.1021/jf070601a PMid:17595106.

5. Hilal $Y$, Engelhardt U. Characterization of white tea-comparison to green and black tea. J. Vergbr. Lebensm. 2007:2:414-21. https://doi.org/10.1007/s00003007-0250-3

6. Unachukwu U. J. 2010. White and green teas (Camellia sinensis var.sinensis): variation in phenolic, methylxanthine, and antioxidant profiles. Journal of Food Science. 2010;75(6):541-8. Available from http://dx.doi.org/ 10.1111/j.17503841.2010.01705.x https://doi.org/10.1111/j.1750-3841.2010.01705.x.

7. Thring TS, Hili P, Naughton DP. An antioxidant and potential anti-inflammatory activity of extracts and formulations of white tea, rose, and witch hazel on primary human dermal fibroblast cells. J Inflamm (Lond). 2011:8:27. https://doi. org/10.1186/1476-9255-8-27 PMid:21995704 PMCid:PMC3214789.

8. Elya B, Hand R, Sauriasari R, Hassyati US, Permana IT, Permatasari YI. Activity antidiabetic and phytochemical screening of extract from Indonesian plants by inhibition of alpha-glucosidase and dipeptidyl peptidases IV. Pakistan Journal of Biological Science. 2015:18(6):279-84. https://doi.org/10.3923/ pjbs.2015.279.284.

9. World Health Organization, Quality Control Methods for Medicinal Plant Materials. Geneva: 1998

10. Harborne JB. Methods of Phytochemistry, Kosasih, P. and I. Soediro (Eds.) Bandung: Publisher ITB; 1987. PMid:3691654.

11. Mahmood T, Akhtar N, Khan BA. The Morphology. Characteristics and medicinal properties of Camellia sinensis' tea. Journal of Medicinal Plants Research. 2010:4(19):2028-33. https://doi.org/10.5897/JMPR10.010.

12. Europian Pharmacopoeia Comission, Europian Pharmachopoeia 5th Edition; 2005: 215.

13. Cheruiyot EK, Mumera LM, Ng'etich WK, Hassanali A, Wachira F. Polyphe$\mathrm{nol}$ as potential indicators for drought tolerance in tea (Camellia sinensis L.) Biosci, Biotech., and Biochemistry, 2007:71(9):2190-7. https://doi.org/10.1271/ bbb.70156 PMid:17827703.

14. Chaturvedula VSP, Prakash I. The Aroma, Taste, Color and Bioactive Constituent of Tea. Journal of Medicinal Plants Research. 2011:5(11):2110-24.

15. Gondoin A, Grussu D, Stewart D, McDougall G. J. White and green tea polyphenols inhibit pancreatic lipase in vitro. Food Research International. 2010:43:p.1537-44. https://doi.org/10.1016/j.foodres.2010.04.029

16. Sohle J, Knott A, Holtzmann U, Siegner R, Gronniger E, Schepky, A, et al. White tea extract induced lipolytic activity an inhibits adipogenesis in human subcutaneous (pre)-adipocytes. Nutrition and Metabolism, 2009:6:20. https://doi. org/10.1186/1743-7075-6-20 PMid:19409077 PMCid:PMC2685800. 


\section{ABOUT AUTHORS}

Meiliza Ekayanti: Researcher of Pharmacy Faculty Universitas Indonesia

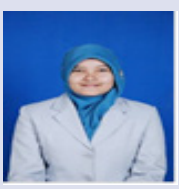

Sarah Zielda Najib: Researcher of Pharmacy Faculty Universitas Indonesia

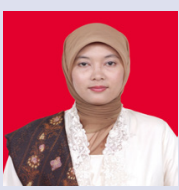

Lia Ardiana: Researcher of Pharmacy Faculty Universitas Indonesia

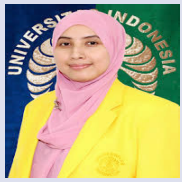

Rani Sauriasari: Lecturer and Researcher of Pharmacy Faculty Universitas Indonesia

Berna Elya: Lecturer and Researcher of Pharmacy Faculty Universitas Indonesia

Cite this Article: Ekayanti M, Ardiana L, Najib SZ, Sauriasari R, Elya B. Pharmacognostic and Phytochemical Standardization of White Tea Leaf (Camellia sinensis L. Kuntze) Ethanolic Extracts. Pharmacogn J. 2017;9(2):221-6. 